\section{FRI0095 PILOT STUDY OF THE EARLY RHEUMATOID ARTHRITIS DIAGNOSIS PROGRAM WITH A STRUCTURED REFERRAL FORMAT}

J. Jaimes-Hernandez ${ }^{1}$, P. Aranda-Pereira ${ }^{2}$, C.I. Melendez-Mercado ${ }^{2}$, A. Mendoza-Fuentes $^{2}$, I. Guzman-Sanchez ${ }^{2}$, R.M. Rodriguez-Romo ${ }^{3}$. ${ }^{1}$ Rheumatology Department, ISSEMYM Toluca Medical Center, Toluca, State of Mexico; ${ }^{2}$ Rheumatology Department, ISSEMYM, Toluca; ${ }^{3}$ Rheumatology, Mexican College of Rheumatology, Mexico City, Mexico

Background: The delay in referral of patients with suspicion of Undifferentiated Inflammatory Arthritis (UIA), especially the Rheumatoid Arthritis (RA), from the primary care physician (PCP) to the Rheumatologist prevents diagnosing and treatment in a timely manner. Early diagnosis and treatment decreases progression and permanent joint damage. Several strategies have been proposed to improve the time to referral of patients with UIA, however there is none for early RA in specific.

Objectives: We present a pilot study for the use of a weighted construct format for the improvement of the time to referral of patients with suspicion of early RA. Methods: Since June 2005, in clinics and hospitals, PCPs were trained for the use of the weighted construct format tool. Adult patients with less than 1year of symptoms were considered for the referral. The criteria for reference of suspicion of early RA are shown in Table 1. The patient referral was made through the counter-reference system, including the complete format and laboratory results. The patient's appointment was given within 15 business days. Once the patients were evaluated and studied in the Department of Rheumatology, they were classified with RA according to 2010 ACR/EULAR criteria when was available this criteria classification. For the demographic variables, we used descriptive and inferential statistics and for the format validation we verified the reliability, and validity of the construct and criterion tool.

Results: Between July 2005 and July 2015, 298 patients were referred to our clinic. The average referral time in the first year (2005-2006) was $34.3 \pm 20.4$ days, maintaining an average of $32.1 \pm 16.8$ days until 2015. There was a reduction of $74 \%$ of referral time compared to a historical reference (mean time of referral was $127.4 \pm 51.8$ days, in 122 patients). 182 (62\%) patients filled out the 2010 ACR/EULAR criteria. The referral format for early RA had a Cronbach alpha of 0.49 , Sensitivity $85.1 \%$, Specificity $93.5 \%$ and PPV $92.2 \%$. The correlation Table 1

\begin{tabular}{|c|c|c|c|}
\hline & Criteria & Score & Total \\
\hline \multirow{4}{*}{ Clinical } & Polyarticular arthritis: $>5$ joints & & \\
\hline & $\begin{array}{l}\text { Small joints: proximal interphalangeal joints, } \\
\text { metacarpophalangeal joints, metatarsophalangeal or wrist } \\
\text { jointst any large joint (shoulders, elbows, knees or ankles) }\end{array}$ & 4 & \\
\hline & Morning stiffness greater than 30 minutes $\left(>30^{\prime}\right)$. & 3 & \\
\hline & Oligoarticular arthritis: $<5$ joints (small and large joints). & 0 & \\
\hline \multirow{4}{*}{ Laboratory } & $\begin{array}{l}\text { Rheumatoid factor (+): dilution >1:160 or } 20 \text { IU for } \\
\text { nephelometry or turbidimetry. }\end{array}$ & 4 & \\
\hline & $\begin{array}{l}\text { Ervthrocyte sedimentation rate (ESR) or C-reactive protein } \\
\text { (CRP): positive (> than normal reference parameter). }\end{array}$ & 3 & \\
\hline & $\begin{array}{l}\text { Anemia: hemoglobin }(\mathrm{Hb}) \leq 12.5 \mathrm{~g} / \mathrm{dl} \text { or } \\
\text { thrombocytosis }>40 \times 10^{3} / \mathrm{pl} \text { platelets. }\end{array}$ & 1 & \\
\hline & Total & 15 & \\
\hline
\end{tabular}

$\leq 5$ points low suspect, between $\geq 6$ and $\leq 10$ suspect, and $\geq 11$ points highly suspect. Clinical criteria: obtained through complete clinical history (morning stiffness: time it takes to mobilize a joint after waking up). Musculoskeletal examination should show joint swelling (swelling, tenderness, temperature increase and difficulty to mobilize). Laboratory: obtained within the protocol that caused the patient's visit (no $>2$ weeks) results must be attached.

Abstract FRI0096 - Table 1

\begin{tabular}{|c|c|c|c|c|c|c|c|}
\hline & & $\begin{array}{c}\text { RA-BEGIN } \\
\text { Bari } 4 \mathrm{mg} \\
\mathrm{N}=30\end{array}$ & $\begin{array}{c}\text { RA-BEAM } \\
\text { Bari } 4 \mathrm{mg} \\
\mathrm{N}=104\end{array}$ & $\begin{array}{c}\text { RA-BUILD } \\
\text { Bari } 2 \mathrm{mg} \\
\mathrm{N}=154\end{array}$ & $\begin{array}{c}\text { RA-BUILD } \\
\text { Bari } 4 \mathrm{mg} \\
\mathrm{N}=164\end{array}$ & $\begin{array}{c}\text { RA-BEACON } \\
\text { Bari } 2 \mathrm{mg} \\
\mathrm{N}=117\end{array}$ & $\begin{array}{c}\text { RA-BEACON } \\
\text { Bari } 4 \mathrm{mg} \\
\mathrm{N}=124\end{array}$ \\
\hline \multicolumn{8}{|c|}{ Durability of Response, $\mathrm{n}(\%)$} \\
\hline \multirow{5}{*}{$\mathrm{SDAl} \leq 11$} & Wk12 OS & $13(43.3)$ & $48(46.2)$ & 59 (38.3) & 69 (42.1) & $31(26.5)$ & $46(37.1)$ \\
\hline & Wk24 OS & $18(60.0)$ & 59 (56.7) & $87(56.5)$ & $106(64.6)$ & $40(34.2)$ & 56 (45.2) \\
\hline & Wk52 OS & $23(76.7)$ & $74(71.2)$ & & & & \\
\hline & Wk48 LTE & $23(76.7)$ & 77 (74.0) & $98(63.6)$ & $106(64.6)$ & $54(46.2)$ & $62(50.0)$ \\
\hline & Wk96 LTE & 25 (83.3) & $73(70.2)$ & $86(55.8)$ & $92(56.1)$ & $54(46.2)$ & $62(50.0)$ \\
\hline \multirow[t]{5}{*}{ HAQ-DI imp $\geq 0.22$} & Wk12 OS & 28 (93.3) & 80 (76.9) & $118(76.6)$ & $118(72.0)$ & 85 (72.6) & 97 (78.2) \\
\hline & Wk24 OS & $27(90.0)$ & 85 (81.7) & $121(78.6)$ & $121(73.8)$ & $88(75.2)$ & 92 (74.2) \\
\hline & Wk52 OS & $24(80.0)$ & $86(82.7)$ & & & & \\
\hline & Wk48 LTE & $25(83.3)$ & $77(74.0)$ & $113(73.4)$ & $115(70.1)$ & $75(64.1)$ & $80(64.5)$ \\
\hline & Wk96 LTE & $26(86.7)$ & 80 (76.9) & $98(63.6)$ & $105(64.0)$ & $58(49.6)$ & 79 (63.7) \\
\hline \multicolumn{8}{|c|}{ Maintenance of Response at 96 wks, $\%\left(n / N^{\prime}\right)$} \\
\hline \multirow[t]{2}{*}{$\mathrm{SDAI} \leq 11$} & $\mathrm{R}$ & $82.6(19 / 23)$ & $81.1(60 / 74)$ & $70.9(61 / 86)$ & $66.7(68 / 102)$ & $77.5(31 / 40)$ & $77.8(42 / 54)$ \\
\hline & NR & $85.7(6 / 7)$ & $43.3(13 / 30)$ & $36.9(24 / 65)$ & $36.2(21 / 58)$ & $27.8(20 / 72)$ & $27.7(18 / 65)$ \\
\hline \multirow[t]{2}{*}{ HAQ-DI imp $\geq 0.22$} & $\mathrm{R}$ & $87.5(21 / 24)$ & $84.9(73 / 86)$ & $72.7(88 / 121)$ & $71.9(87 / 121)$ & $56.8(50 / 88)$ & $71.7(66 / 92)$ \\
\hline & NR & $83.3(5 / 6)$ & $38.9(7 / 18)$ & $30.3(10 / 33)$ & $39.0(16 / 41)$ & $27.6(8 / 29)$ & $40.6(13 / 32)$ \\
\hline
\end{tabular}

between patients with early RA and the $2010 \mathrm{ACR} / \mathrm{EULAR}$ criteria was 0.765 with a $p<0.000$.

Conclusions: In this pilot study, we observed that the construct had a suitable sensitivity, specificity and PPV for a referral format. Therefore, on suspicion of early RA the referral format could be useful as a simple clinical tool for the timely referral to the Rheumatologist. On the other hand, the program implementation allowed the reduction in the referral time substantially. To implement the use of this tool in the daily clinical practice it needs to be validated with an open population and an adequate sample size

References:

[1] Emery P,Breedveld F C,Dougados M,Kalden J R,Schiff M H,Smolen J S. Early referral recommendation for newly diagnosed rheumatoid arthritis:evidence based development of a clinical guide. Ann Rheum Dis 2002;61:290-297.

[2] Villeneuve E,Nam JL,Bell MJ,Deighton CM,Felson DT, Et al, A systematic literature review of strategies promoting early referral and reducing delays in the diagnosis and management of inflammatory arthritis. Ann Rheum Dis 2013;72:13-22.

[3] Deane KD,Striebich CC,Goldstein BL, et al. Identification of undiagnosed inflammatory arthritis in a community health fair screen. Arthritis Rheum 2009;61:1642-9.

Disclosure of Interest: None declared

DOI: 10.1136/annrheumdis-2017-eular.2561

\section{FRI0096 DURABILITY AND MAINTENANCE OF EFFICACY FOLLOWING PROLONGED TREATMENT WITH BARICITINIB}

J.S. Smolen ${ }^{1}$, Z. Li ${ }^{2}$, R. Klar ${ }^{3}$, L. Xie ${ }^{4}$, D. Walker ${ }^{4}$, A. Ghizdavescu ${ }^{4}$, R. Ortmann ${ }^{4}$, M. Dougados ${ }^{5} .{ }^{1}$ Medical University of Vienna, Vienna, Austria; ${ }^{2}$ Peking University People's Hospital, Beijing, China; ${ }^{3}$ Quintiles IMS Holdings, Inc., Durham; ${ }^{4}$ Eli Lilly and Company, Indianapolis, United States; ${ }^{5}$ Hôpital Cochin, Paris Descartes University, Paris, France

Background: Baricitinib (bari) demonstrated clinical efficacy in Ph3 trials in RA patients (pts) naïve to DMARDs (RA-BEGIN ${ }^{1}$ ); and in RA pts with inadequate response to conventional synthetic DMARDs (RA-BEAM ${ }^{2}$ and RA-BUILD ${ }^{3}$ ) or biologic DMARDs (RA-BEACON ${ }^{4}$ ).

Objectives: To evaluate durability and maintenance of efficacy over an additional 96 weeks (wks) of bari treatment.

Methods: Pts included were those randomised to bari in an originating study (OS), completed that study without rescue (52 wks in RA-BEGIN or RA-BEAM; 24 wks in RA-BUILD or RA-BEACON), and entered the long-term extension (LTE) study $\geq 96$ wks prior to data cut-off. Durability of response was evaluated as pts achieving low disease activity (LDA) of SDAI $\leq 11$ and minimal clinically important difference (MCID) of HAQ-DI improvement $>0.22$. Maintenance of response was evaluated as proportion of pts who had responded to bari at entry into LTE and maintained response at wk 96. Data are also provided for pts who had not responded to bari at entry into LTE who achieved response.

Results: Approximately half the pts in the durability analyses were categorised as LDA by wk 24 and the proportion of pts in the LDA category were similar or higher at wk 96. Three quarters of pts across groups demonstrated HAQ-DI improvement by wk 12 and more than half achieved MCID at wk 96. Most responders at entry into LTE maintained their response through wk 96 . More than $25 \%$ of SDAI and HAQ-DI nonresponders at entry into LTE achieved response after 96 wks of treatment.

Conclusions: These data provide further evidence of the effectiveness of bari treatment in achievement of meaningful clinical control of disease activity long term.

References:

[1] Fleischmann R et al. Arthritis Rheumatol 2016.

[2] Taylor P et al. Arthritis Rheumatol 2015;67(Suppl10).

[3] Dougados M et al. Ann Rheum Dis 2017.

[4] Genovese MC et al. N Eng J Med 2016. 